\title{
o Alinhamento entre a Teoria Ator-Rede e a Sociologia Relacional: uma Discussão Onto- Epistemológica para os Estudos Organizacionais
}

\author{
Alignment between Actor-Network Theory and Relational Sociology: an Onto- \\ Epistemological Discussion for Organizational Studies
}

\author{
Eduardo Guedes Villar \\ Universidade Federal do Paraná - UFPR - Brasil \\ eduardogvillar@gmail.com \\ ORCID: 0000-0001-5005-4099 \\ Karina De Déa Roglio \\ Universidade Federal do Paraná - UFPR - Brasil \\ karinaroglio@gmail.com \\ ORCID: 000-0002-5256-8330
}

Submetido em 18/03/2018; Aprovado em 30/09/2018

\begin{abstract}
Resumo
Neste artigo de revisão de literatura busca-se explorar o alinhamento entre a sociologia relacional e a teoria ator-rede e possíveis repercussões deste alinhamento para as pesquisas em organizações. Para isso, realizou-se a revisão dos principais autores de cada abordagem, pontuando alguns aspectos do seu posicionamento ontológico, epistemológico e metodológico. Em complemento, utilizou-se uma estrutura de classificação de paradigmas sociológicos para discutir o alinhamento das abordagens, revelando convergências e divergências entre ambas. Explorou-se, ainda, como a aproximação entre essas abordagens sociológicas pode auxiliar a área de estudos organizacionais a (i) reconsiderar a própria noção de organização, (ii) (re)conceituar os processos organizativos, (iii) repensar a questão da agência no processo organizativo. Por fim, são apresentadas oportunidades de pesquisa que versam sobre a inclusão do tempo nas explanações teóricas da área, dar voz à materialidade e aos elementos não humanos em suas observações e aproximar-se das experiências sociais das pessoas em busca de explicações que ressoam a realidade das organizações.
\end{abstract}

Palavras-Chave: sociologia relacional; sociologia transacional; teoria ator-rede; ontologia; epistemologia.

\section{Abstract}

We aim to explore in this paper the alignment between relational sociology and actor-network theory and the possible repercussions of this alignment to organizational studies. Therefore, the main authors of each approach were reviewed, and their ontological, epistemological and methodological positioning were highlighted. In addition, we adopted the structure of sociological paradigms' classification to discuss the alignment between these approaches, revealing the convergences and divergences between them. We also explored how the approximation between these sociological lenses could help the organizational studies field (i) rethinking the very notion of organization, (ii) re-conceptualizing organizational processes, (iii) rethinking the agency issue in the organizational process. Finally, research opportunities were presented, which embraces the inclusion of time in the theoretical explanations of the area, giving voice to the materiality and to nonhuman elements in its observations and to get closer of people's social experiences looking for explanations that resonate organizations' realities.

Keywords: relational sociology; transactional sociology; actor-network theory; ontology; epistemology.

\section{Introdução}

A partir da década de 1990 surgiu uma corrente de análise filosófica sob o rótulo de pósmodernismo (Hassard \& Cox, 2013). Apesar de não apresentar um único grupo coeso de pensamento, o pós-modernismo questiona as abordagens tradicionais que discutem a interação entre estrutura e 
agência. Dentre as abordagens que emergem desta corrente, estão a Sociologia Relacional (Emirbayer, 1997) e a Teoria Ator-Rede (Actor-Network Theory - ANT) (Law, 1992). A sociologia relacional desenvolve-se a partir do questionamento: (i) do poder de "super-entidades" (estruturas) agindo diretamente sobre o indivíduo, e (ii) da aparente capacidade imanente do indivíduo de deliberar sobre a realidade (agência) (Emirbayer, 1997). A Teoria Ator-Rede parte de uma tradição antropológica (Law, 1992; Latour, 2005), em que se concebe o mundo social como composto de redes de associações entre uma variedade de atores, humanos e não humanos, as quais são estendidas espaço-temporalmente (Latour, 2005).

As duas abordagens tradicionalmente representam correntes de pesquisa diferentes, com divergências no entendimento ontológico do social e com interesses distintos no que se refere ao campo de pesquisa. Contudo, acredita-se que os recentes trabalhos da sociologia da transação (Dépelteau, 2015; Burkitt, 2016) e da sociologia relacional profunda (Dépelteau, 2013) de um lado, e o trabalho "remontando o social" (Latour, 2005) de outro, apresentam o desenvolvimento dos campos de estudo e, em decorrência, uma oportunidade de aproximação destas abordagens. 0 imbricamento entre estas abordagens também se justifica pela possibilidade de fortalecimento mútuo, com vistas à solidificação de um paradigma de pesquisa embasado no prisma da ontologia da relacionalidade. A Sociologia Relacional traz um amadurecimento teórico a partir de temas-chaves para a sociologia como estrutura, agência e poder (Emirbayer, 1997). Em contrapartida, a Teoria Ator-Rede adiciona um vasto espectro metodológico embasado em pesquisas vivenciais (Callon, 1986, Latour \& Woolgar, 1986, Latour, 1987). Ou seja, a herança de discussão teórica da qual culmina a Sociologia Relacional profunda (Dépelteau, 2013) pode ajudar a Teoria Ator-Rede a esclarecer os hiatos teóricos da abordagem (Collins \& Yearley, 1992). Em complemento, a expertise metodológica advinda dos estudos realizados a partir da Teoria Ator-Rede (Law, 2004) pode auxiliar a explorar empiricamente as "relações reais" discutidas apenas sob o prisma teórico na Sociologia Relacional (Dépelteau, 2013, p.184), respeitando inclusive a participação dos atores não humanos.

As discussões sobre estrutura e agência são as duas principais ordens de atenção teórica para as teorias social e organizacional (Reed, 1997). Nesta última, tem-se verificado a falta de inovação teórica (Suddaby, Hardy, \& Huy, 2011) e, principalmente, a carência de aderência das teorias existentes à realidade das organizações (Tsoukas, 2017). Neste sentido, a aproximação a partir de ontologias mais planas ou relacionais (Chia \& Holt, 2006) - dentre as quais incluem-se as teorias exploradas neste trabalho - possibilita investigações mais abertas ao empírico e proporciona a possibilidade de o pesquisador mover-se teórico-conceitualmente em situações em que as teorias existentes oferecem poucas explicações (Seidl \& Whittington, 2014). A investidura a partir da ontologia relacional ou plana permite, ao pesquisador, descrever a agência como envolvendo a relacionalidade de lugares e passados, ao invés de uma nítida distinção entre o indivíduo pré-formado e o ambiente (Chia \& Holt, 2006).

Em adição, a área de estudos organizacionais tem seu desenvolvimento pautado por pesquisas orientadas pela busca por gaps (Sanderson \& Alvesson, 2011), as quais promovem a manutenção dos pressupostos da literatura existente. Ou seja, preocupa-se em refinar a literatura da área até encontrar alguma articulação que outros autores não encontraram ou buscar por mais dados e informações empíricas sobre o fenômeno que se quer estudar (Weick, 2001). Contudo, nesta busca por gaps acabase apenas reforçando os pressupostos já estabelecidos (Alvesson \& Sandberg, 2011). Para que se alcance a oxigenação teórica requerida na área (Suddaby, Hardy, \& Huy, 2011), faz-se necessário questionar os pressupostos existentes em seu próprio corpo teórico, o que Alvesson \& Sandberg (2011) denominam de orientação para a problematização. As abordagens sociológicas exploradas neste trabalho de revisão de literatura, por apresentarem abordagens ontológicas mais flexíveis (Latour, 2005) sem determinar propriedades intrínsecas (Emirbayer, 1997), podem ajudar neste exercício de problematização dos pressupostos teóricos, conforme sugerido por Alvesson \& Sandberg (2011). Para tanto, neste estudo busca-se explorar o alinhamento entre a sociologia relacional e a teoria ator-rede e as suas repercussões para a área de estudos organizacionais. Acredita-se que a aproximação entre as abordagens permite fortalecer um posicionamento relacional de pesquisa em estudos organizacionais, advindos principalmente do debate da questão da agência, dada a herança sociológica desta área de estudos. E também, em decorrência deste posicionamento, inserir o papel dos elementos não humanos até então relegados em abordagens de cunho preponderantemente humanistas e estruturalistas (McFarlane, 2013).

Esta pesquisa foi desenvolvida por meio da revisão da literatura da Sociologia Relacional e da ANT. 
Na segunda seção, apresenta-se o resultado desta revisão e evidenciam-se os posicionamentos ontológicos, epistemológicos e metodológicos de cada corrente de pensamento e também a discussão sobre a possível aproximação das duas perspectivas teóricas. Na terceira seção, debatem-se as repercussões dessa aproximação para a área de estudos organizacionais. E na quarta seção discute-se as contribuições do presente trabalho e algumas recomendações para pesquisas futuras.

\section{Revisão de literatura}

Nesta seção são apresentadas duas abordagens teóricas que embasam esse trabalho de revisão de literatura. A revisão foi feita por meio de leitura não exaustiva dos principais autores de cada área com propósito de identificar as principais definições, conceitos e concepção, bem como alguns aspectos relacionados ao posicionamento ontológico, epistemológico e metodológico de cada abordagem.

\subsection{Sociologia Relacional}

Sociologia Relacional é definida por um grupo específico de especialistas que compartilham conceitos básicos e suposições gerais sobre princípios ontológicos, epistemológicos, teóricos e metodológicos (Dépelteau, 2013). A formação deste 'paradigma' foi consolidada por Emirbayer (1997), mas o próprio autor sugere que a concepção relacional de análise vinha sendo trabalhada por uma variedade de perspectivas teóricas e empíricas anteriores, remetendo inclusive ao pensamento présocrático.

A sociologia relacional pode ser associada, segundo Dépelteau (2013), as mais variadas teorias e redes intelectuais. Contudo, não se trata de uma teoria ou um conjunto de técnicas de pesquisa complicadas, mas uma "nova e abrangente família de estratégias analíticas" (p. 164). Em outras palavras, a sociologia relacional se expressa em um paradigma para o estudo de "como os recursos, bens e até posições fluem por meio de determinadas formas de vínculos sociais" (Emirbayer, 1997, p. 298).

Neste sentido, os sociólogos relacionais não apresentam uma visão consensual da área, principalmente no que se refere ao caráter ontológico (Dépelteau, 2013). Contudo, Donati (2011) e Burkitt (2016) indicam que todos eles apresentam concordância quanto a seguinte afirmação: “... no início há a relação" (Donati, 2011, p. 17). Ou seja, ao contrário de toda uma tradição filosófica de substância (Nayak \& Chia, 2011), esses pesquisadores procuram alternativas analíticas que revertam a suposição básica de que entidades vêm primeiro, isto é, possuem propriedades intrínsecas. Para Emirbayer (1997) o intuito de um pesquisador ligado a uma abordagem relacional consiste em retratar a realidade social em termos dinâmicos, contínuos e processuais. Portanto, a questão central que os sociólogos relacionais enfrentam não está mais alicerçada nas dicotomias "material versus ideal"; "estrutura versus agência"; "indivíduo versus sociedade" (Emirbayer, 1997). Para o autor, a escolha principal se dá entre o substancialismo e o relacionalismo.

No substancialismo tem-se como ponto de partida a substância, sejam coisas, seres ou essências; a qual constitui a unidade básica da investigação (Emirbayer, 1997). Como exemplo de uma aproximação substancialista, pode-se indicar a teoria da escolha racional, na qual a unidade elementar da vida social é a ação humana individual. Os indivíduos possuem identidades próprias e não problemáticas, são dotados de autonomia e liberdade para agir e realizam escolhas deliberadas. Portanto, o propósito e a intencionalidade são características em destaque no comportamento do indivíduo (Nayak \& Chia, 2011). Em suma, a análise numa perspectiva de substância começa sempre a partir de "entidades auto subsistentes e pré-formadas" (Emirbayer, 1997, p.228), e só posteriormente considera-se o fluxo dinâmico em que estas se envolvem. Além da teoria da escolha racional exemplificada anteriormente, o pensamento estruturalista, mecanicista e de variância também corresponde ao substancialismo (Mützel, 2009).

Em contrapartida, em uma perspectiva relacional busca-se um modelo de análise mais dinâmico e contextual, considerando como o significado surge em um contexto relacional e, também, como as relações criam significado (Mützel, 2009). Ao invés de buscar vínculos estáticos entre substâncias inertes, nesta abordagem percebem-se relações entre termos ou unidades como de natureza preeminentemente dinâmica (Emirbayer, 1997). Os indivíduos são considerados como inter-actants ${ }^{* 1}$, ou seja, seres em interação ${ }^{* 2}$ e não agentes ou atores singulares (Burkitt, 2016). Esse autor ainda afirma que a terminologia da 'estrutura' é abandonada em favor da análise das conexões relacionais entre os interagentes (inter-actants). Ou seja, tornam-se redes de relações e interdependências, em que os interagentes e suas ações conjuntas são incorporados (Burkitt, 2016). Os teóricos relacionais rejeitam a 
noção de que se pode postular unidades discretas, pré-formadas, como o indivíduo ou a sociedade, como pontos de partida da análise sociológica. Pessoas individuais independente da atuação que exercem, são inseparáveis dos contextos transacionais em que estão inseridas (Emirbayer, 1997).

Com o intuito de organizar a diversidade histórica de entendimentos existentes dentro da perspectiva relacional, Dépelteau (2013) sugere três amplas correntes de pensamento: (i) determinista; (ii) co-determinista; (iii) relacional profunda. Para o autor, essas constelações intelectuais são mais do que categorias nominais, uma vez que se baseiam em visões de mundo comuns e influências filosóficas ou sociológicas mais ou menos compatíveis. Na Figura 1, são apresentadas as principais características dessas três correntes de pensamento:

Figura 1: Correntes de Pensamento da Perspectiva Relacional

\begin{tabular}{|l|l|l|l|l|}
\hline $\begin{array}{c}\text { Abordagem } \\
\text { Ontológica }\end{array}$ & $\begin{array}{l}\text { Postura } \\
\text { Epistemológica }\end{array}$ & \multicolumn{1}{|c|}{ Estrutura - Agência } & \multicolumn{1}{c|}{ Relação } & Autores \\
\hline Determinista & Self-Action & $\begin{array}{l}\text { Estruturas como totalidades } \\
\text { ou "redes ordenadas", } \\
\text { determinam as partes } \\
\text { (atores). Agência é } \\
\text { negligenciada. }\end{array}$ & $\begin{array}{l}\text { Os 'padrões sociais' simplesmente } \\
\text { determinam ações individuais. O poder } \\
\text { causal da estrutura como fenômeno } \\
\text { objetivo. }\end{array}$ & $\begin{array}{l}\text { Durkheim; } \\
\text { Parsons. }\end{array}$ \\
\hline $\begin{array}{l}\text { Co- } \\
\text { Determinista }\end{array}$ & Interação & $\begin{array}{l}\text { Os poderes dos indivíduos } \\
\text { interagem com os poderes } \\
\text { causais das estruturas sociais } \\
\text { (Dualismo analítico). }\end{array}$ & $\begin{array}{l}\text { Os efeitos estruturais são ainda } \\
\text { reconhecidos, mas os atores não são } \\
\text { simplesmente seus portadores. Há a } \\
\text { possibilidade de um efeito causal direto } \\
\text { entre um 'padrão social' e um indivíduo. }\end{array}$ & $\begin{array}{l}\text { Giddens; } \\
\text { Archer. }\end{array}$ \\
\hline $\begin{array}{l}\text { Sociologia } \\
\text { Relacional } \\
\text { Profunda ou } \\
\text { Transacional }\end{array}$ & Transação & $\begin{array}{l}\text { Tudo é social ou } \\
\text { interdependente. As } \\
\text { estruturas sociais não podem } \\
\text { interagir com os atores. Nada } \\
\text { vem simplesmente de } \\
\text { qualquer capacidade interna } \\
\text { (do indivíduo). }\end{array}$ & $\begin{array}{l}\text { As relaçóes são complexas e não podem } \\
\text { ser explicadas com a ideia de que } \\
\text { grandes "estruturas sociais" interagem } \\
\text { com indivíduos. Transação refere-se a } \\
\text { estados de interdependência mais } \\
\text { abrangentes nos quais o indivíduo se } \\
\text { encontra sempre em vários campos de } \\
\text { transação. }\end{array}$ & $\begin{array}{l}\text { Burkitt; } \\
\text { Dépelteau; } \\
\text { Emirbayer. }\end{array}$ \\
\hline
\end{tabular}

Fonte: Elaborado pelos autores com base em Dépelteau (2013)

Com base na análise da Figura 1, no que se refere à postura epistemológica, Dépelteau (2013) resgata a classificação feita por Dewey e Bentley (1949). A auto-ação (self-action) refere-se ao voluntarismo ou determinismo social, ou seja, a estrutura ou o sujeito auto-agem sobre algo/alguém. A interação (inter-action) reflete uma aproximação co-determinista em que o social consiste na interação entre estrutura e agência. E a transação (trans-action) é a que estará relacionada a um pensamento relacional mais profundo (Dépelteau, 2013).

No que concerne à conceituação de estrutura e agência, nas duas primeiras concepções (determinista e co-determinista) a estrutura pode ser concebida como algo externo ao indivíduo (sociedade, regras e recursos, propriedades culturais e estruturais) e a agência como uma propriedade intrínseca do indivíduo (poderes cognitivos reflexivos) (Burkitt, 2016). Em uma abordagem determinista sugere-se que 'padrões de relações' que podem ser identificados por meio da observação da relação humana determinam as ações individuais (Dépelteau, 2013). Segundo esse autor, tais padrões possuem um poder causal sobre os atores sociais, como se fossem fenômenos objetivos. Ou seja, a estrutura revelada como totalidade determina as partes (atores). Neste sentido, a capacidade de agência dos atores é negligenciada (Burkitt, 2016).

Por sua vez, as abordagens co-deterministas buscam "encontrar o equilíbrio entre a agência e as estruturas ou explicar a conexão entre essas duas forças contraditórias” (Dépelteau, 2013, p. 182). A aproximação co-determinista caracteriza-se pela discussão de como ocorre a interação entre estrutura e agência. Essa interação pode se dar como dualidade (Giddens, 1984) ou como dualismo analítico (Archer, 1995). Respeitando-se as diferenças entre múltiplas teorias co-deterministas, para Dépelteau (2013), estas se baseiam na ideia de que a história é o efeito das interações entre as propriedades das estruturas sociais e da agência humana. Em outras palavras, os efeitos estruturais são ainda reconhecidos, mas os atores não são simplesmente seus condutores.

A abordagem relacional profunda ou sociologia transacional (Emirbayer, 1997; Burkitt, 2016) rejeita qualquer forma de determinismo social. Dépelteau (2013) justifica a rejeição em virtude da incapacidade das abordagens anteriores de explicar a mudança social, a reificação das estruturas sociais, 
das culturas e das instituições e a supressão das pessoas que são vistas como portadores das estruturas sociais. Para a sociologia relacional, os padrões sociais existem e podem ser explicados. Mas o nível de semelhança de comportamentos e relacionamentos é sempre uma questão de gradação, uma vez que ações e relacionamentos são apenas mais ou menos semelhantes ou diferentes e, portanto, não podem ser simplesmente objetivados (Dépelteau, 2013).

Dépelteau (2013) sugere que as estruturas sociais são fenômenos transacionais (relacionais) porque (i) são transações entre pessoas, e (ii) não podem interagir com os atores, basicamente porque as ações humanas derivam da percepção dos objetos e não dos próprios objetos. Os indivíduos podem somente ser influenciados por suas próprias percepções de padrões de relações, que estão relacionadas com "suas próprias experiências, memórias do passado, objetivos, desejos, emoções, etc." (Dépelteau, 2013, p. 185). Em decorrência, não pode haver um efeito causal simples ou direto entre um padrão social e uma pessoa.

Emirbayer (1997) complementa que relações entre padrões sociais e indivíduos são complexas e, portanto, não podem ser explicadas com a ideia de que grandes "estruturas sociais" interagem com os indivíduos. Em complemento, também não há uma agência pura, ou seja, nada decorre simplesmente de alguma capacidade interna. Para Dépelteau (2013) "nada é isolado, tudo é social ou interdependente" (p. 186).

Após delinear as diversas correntes do pensamento relacional, será detalhado o pensamento da sociologia da transação (Emirbayer, 1997) ou sociologia relacional profunda (Dépelteau, 2013) com vistas a explorar seus aspectos ontológicos, epistemológicos e metodológicos. No que confere ao aspecto ontológico, a relação é o ponto de partida (Donati, 2011), e a definição de sujeito e objeto só pode se dar relacionalmente. Ou seja, conceitos não podem ser definidos como entidades ontológicas simples (Emirbayer, 1997), pois um conceito só pode ser decifrado diante de seu lugar em relação aos outros conceitos em sua rede de relação. Neste sentido, o indivíduo atua em múltiplas redes de interdependência, nas quais ele nunca é totalmente independente ou dependente, uma vez que opera em algum lugar no contínuo entre estas duas abstrações (Burkitt, 2016).

Burkitt (2016) afirma que estas relações possuem uma história e, portanto, não podem ser reduzidas simplesmente a agências passadas ou reificadas como estrutura. As relações são relativamente fluidas e contínuas (algumas mais duradouras do que outras), "a medida que as pessoas entram e saem em diferentes momentos de redes de relações, e também porque as próprias relações têm que se adaptar às circunstâncias atuais" (p. 330). 0 cerne do pensamento relacional consiste em sua profundidade ontológica, pois não são simplesmente relações, e os objetos e entidades produzidos nas relações. 0 foco está sobre as relações sociais e o modo de vida que os seres humanos produzem por meio delas, incluindo a cultura material e a tecnologia, que os sociólogos relacionais necessitam trazer para a análise (Burkitt, 2016).

Em termos epistemológicos, a sociologia relacional profunda caracteriza-se pelo aspecto transacional (Emirbayer, 1997). Nesta abordagem as relações acontecem apenas entre entidades individuais, as quais não possuem propriedades intrínsecas. Burkitt (2016) indica que as organizações não são entidades sui generis, mas "fluidas e mutáveis em relação a sua forma" (p. 333). A organização, por exemplo, é o resultado permanente e mutável das relações externas e internas, e esta, por sua vez, também afetará a relação com aqueles que são 'dependentes' dela (Burkitt, 2016). Na seguinte passagem, Dépelteau (2013) advoga por uma teoria do conhecimento relacional:

Talvez tudo o que podemos saber acontece no único "nível" de realidade social que temos: o nível de campos de transação muito específicos onde nós fazemos uns aos outros como amantes, amigos, pessoas que cuidam, que odeiam, inimigos ou pessoas egocêntricas, as quais podem apoiar ou machucar um ao outro. Talvez não haja nada mais do que nós mesmos fazendo o nosso caminho por meio destes vários, complexos, e bastante instáveis campos de transação (Dépelteau, 2013, tradução nossa).

Assim, como atores em transação, nenhum indivíduo é simplesmente um agente ou um paciente em qualquer momento. Para Burkitt (2016) a pessoa é sempre agente e paciente agindo sobre os outros e 'sendo agido' por outros em graus variados. Desta forma, a reflexividade e escolha deliberada também são limitadas em diferentes situações por contingências fora do âmbito reflexivo, uma vez que sujeitos são seres polifônicos que se formam e interagem dentro de redes de relações sociais complexas, fluidas e dialógicas (Dépelteau, 2015).

As metodologias de pesquisa também devem ser alinhadas aos aspectos transacionais ou relacionais, pois envolvem "uma mudança de pensamento sobre um conceito como uma expressão 
categórica singular para conceitos envolvidos em redes relacionais complexas que são intersubjetivas e públicas" (Emirbayer, 1997, p. 300). Segundo Nayak e Chia (2011), "taxonomias, hierarquias, sistemas, estruturas e agentes isoláveis representam o vocabulário instintivo do pensamento institucionalizado, o que leva a subordinação da complexidade dinâmica, da relacionalidade indissociável e da emergência precária que são características de realidade vivenciada" (p. 291, tradução nossa). Neste sentido, ao mesmo tempo em que a sociologia relacional abre novas e excitantes direções de pesquisa (Emirbayer, 1997), é muito fácil reificar total ou parcialmente os fenômenos quando se deixa de pensar de maneira relacional profunda (Dépelteau, 2013).

\subsection{Teoria Ator-Rede}

A Teoria Ator-Rede consiste em uma abordagem originária dos estudos de ciências, tecnologia e sociedade (STS) (Callon \& Law, 1997), e é também denominada por sociologia da tradução (Law, 1992; Callon, 1986), materialidade relacional (Law, 1999) e sociologia da associação (Latour, 2005). Segundo Latour (2005), o nome Actor-Network Theory (ANT) consiste em um nome histórico que, de tão estranho, confuso e sem sentido, merece ser mantido.

Com os conceitos propostos pela ANT não se quer impor certa ordem aos atores estudados ou presumir que eles seguem uma lógica distinta, uma vez que se enfatiza a parcimônia ontológica (Latour, 2005). 0 propósito da ANT consiste em fornecer uma infraestrutura conceitual que evite alegações ontológicas que não sejam empiricamente fundamentadas. Em outras palavras, evitam-se suposições $a$ priori sobre se um fenômeno é macro ou micro, durável e universal ou não, feito pela natureza ou pela sociedade (Bueger, 2013).

Latour (2005) entende que a realidade não possui um status estável e definitivo, sendo composta por redes de materiais heterogêneos (humanos e não humanos) que estão reunidas (Latour, 2013). Assim, a ANT não compõe uma teoria no sentido convencional, mas um repositório de termos e maneiras de se engajar com o mundo e um conjunto de reflexões metodológicas, por vezes contra intuitivos (Callon, 1986). As mudanças no vocabulário, como por exemplo atuante ao invés de ator, ator-rede em vez de relações sociais, tradução em vez de interação, negociação em vez de descoberta, immutable mobiles e inscrições em vez de provas e dados, delegação em vez de papéis sociais, são empregados porque são "termos híbridos que desfocam (blur) a distinção entre a realidade social e os termos centrados em humanos, e a realidade natural e os repertórios centrados em objetos" (Callon \& Latour, 1992, p. 347).

No aspecto ontológico, Latour (2005) sugere que os problemas das abordagens sociológicas ditas modernas, surgem quando "o social começa a significar um tipo de material, como se comparável a outros termos como madeira, aço, biológico, econômico, mental, organizacional ou linguística" (p. 5). Assim, o social não consiste em um domínio especial, um espaço específico ou um determinado tipo de coisa, mas apenas como um movimento peculiar de novas associações (Latour, 2005). 0 autor exemplifica que o social não designa uma coisa entre outras coisas, como uma ovelha negra entre ovelhas brancas, mas compreende um tipo de conexão entre coisas que, por si só, não são sociais. Nas palavras de Latour (2005, p. 107) "o social está de volta como associação", ou seja, circula em toda parte como um movimento de conectar as coisas não sociais.

A sociologia e as demais ciências que se apoiam no pensamento desta acabaram se desvirtuando pelo preconceito em estabelecer um lócus privilegiado de domínio social, onde a ação é mais que a estrutura, o micro é mais que o macro, o indivíduo mais que o coletivo, a interação mais do que a sociedade, ou ao contrário, classes são mais que indivíduo, práticas mais que teorias, órgãos sociais mais do que pessoas (Latour, 2005). Como exemplo do extremo de individualismo, Latour (2005) aponta a noção de racionalidade limitada de Herbert Simon, em que o indivíduo consiste na unidade de análise. E no extremo oposto, o autor indica as diversas sociologias interpretativas, as quais se ocuparam em desenvolver conceitos estruturais, como normas ou instituições. A ANT, ao contrário, não faz essa distinção, pois argumenta que as coisas simplesmente nunca foram divididas em sujeitos e objetos, estrutura e ação, micro e macro, exceto na medida em que as práticas do conhecimento moderno trabalharam para assim dividi-los. Essas divisões, para Latour (2013), são apenas invenções de um projeto de modernidade.

No que se refere ao aspecto epistemológico, Latour (2005) indica que se evite qualquer explicação que dê ao fenômeno social um caráter tridimensional, e se busque mantê-lo totalmente plano. Para o autor, a teoria ator-rede oferece "uma série de grampos para segurar a paisagem firmemente plana e 
forçar qualquer candidato com um papel mais 'global' a sentar-se ao lado do 'local' ao qual pretende explicar" (p. 174). 0 macro não está nem acima e nem abaixo das interações, mas adicionado a elas como qualquer outra de suas conexões, alimentando-as e alimentando-se delas. O que situava 'acima' ou 'abaixo' permanece lado a lado, e firmemente no mesmo plano que os outros loci que este estava tentando ignorar ou incluir (Latour, 2005).

Neste sentido, para poder caminhar dentro desta ontologia do social, Callon (1986) apresenta três princípios norteadores: i) o agnosticismo do observador; ii) a simetria generalizada e iii) a livre associação. No que se refere ao princípio do agnosticismo do observador, Callon e Latour (1992) indicam que as abordagens do social, até então, cometem o erro empírico de acreditar que os cientistas devem ser "realistas ingênuos" para fazer seu trabalho. Quando sugere o agnosticismo do observador, Callon (1986) sustenta que o observador é imparcial, ou seja, nenhum ponto de vista pode ser privilegiado, e nenhuma interpretação censurada. 0 observador não fixa a identidade dos atores implicados se essa identidade ainda está sendo negociada.

Para Latour (2005) o social consiste em um rastro de associações entre elementos heterogêneos, o que sustenta o segundo princípio da simetria generalizada. Nesta proposta, humanos e não humanos são tratados simetricamente e analisados apenas em termos de inter-relações, mediações e traduções (Nimmo, 2011). Assim, a ANT não é um caso de inserção teórica de atores não humanos em uma história de outra maneira centrada no ser humano. Contudo, abstém-se de impor categorizações ontológicas $a$ priori, permitindo assim que emerjam relações heterogêneas. Neste sentido, não existem humanos dissociados de não humanos, uma vez que todos participam conjuntamente de uma rede heterogênea, não podendo ser separados em qualquer situação empírica. Law (1999) sugere que a mesma explicação deveria ser empregada para todos os elementos que compõem uma rede heterogênea, sejam forças naturais ou sociais.

Assim, a simetria generalizada passa a ser uma ferramenta heurística utilizada para entender o papel contingencial exercido pelos atores dentro de uma rede-de-atores (Law, 1992). 0 autor afirma que assumir que não há diferença entre pessoas e objetos não se trata de uma postura ética, mas eminentemente analítica. Ou seja, todos os elementos, humanos ou materiais, participam do ordenamento social (Callon \& Law, 1997), uma vez que a ordem é "o efeito gerado por meios heterogêneos" (Law, 1992, p. 382).

Em complemento, Law (1992) sustenta que a abordagem relacional não celebra a ideia de que não há uma diferença entre as pessoas e objetos, porém nega que as pessoas sejam necessariamente especiais. A ANT não se organiza por meio do estabelecimento de alguma simetria absurda entre os seres humanos e não humanos (Latour, 2005). Ser simétrico, para o autor, significa simplesmente "não impor a priori alguma assimetria espúria entre a ação intencional humana e o mundo material de relações causais" (p. 76).

No que tange ao princípio da livre associação, o terceiro enumerado por Callon (1986), sugerese que o observador deve abandonar todas as distinções a priori entre eventos naturais e sociais, ou seja, necessita-se rejeitar a hipótese de um limite definido que separa ambos. Para o autor, as distinções são consideradas como resultados do processo de análise e não seu ponto de partida. Em vez de impor uma grade pré-estabelecida de análise sobre estas, o observador segue os atores (humanos e não humanos) para identificar a forma como estes definem e associam os diferentes elementos pelos quais constroem e explicam o seu mundo, seja ele social ou natural (Callon, 1986).

Após estabelecidos os princípios básicos da proposta relacional, apresenta-se as definições de ator, ação, agência e rede. Estes conceitos, em virtude da ontologia do social já apresentada, são entendidos diferentemente das abordagens teóricas anteriores, as quais são denominadas de 'sociologia do social' (Latour, 2005).

Em relação ao conceito de ator, embora o termo faça parte do nome da abordagem teórica (Teoria Ator-Rede), Callon \& Latour (1992) preferem o termo atuante (do original 'actante') ao invés do termo 'ator', uma vez que o termo ator sugere uma conotação humana. 0 termo atuante estende-se a todas as entidades, tanto humanas como não humanas. Neste trabalho, a palavra ator será empregada no mesmo sentido de atuante. Ou seja, um ator é um elemento desprovido de conotações unicamente humanas (Callon \& Latour, 1992).

Um ator, na expressão ator-rede, não é a fonte de uma ação, mas o "alvo em movimento de um vasto conjunto de entidades que se aninham em direção a ele" (Latour, 2005, p.46). 0 autor afirma que usar a palavra ator não significa clareza sobre quem ou o que está agindo quando se age, uma vez que 
"um ator em cena, nunca está agindo sozinho" (p. 46). Por nunca estarem sozinhos, os atores humanos existem sempre conjuntamente com outras entidades, as quais congregam uma rede de relações (Law, 1992). Os atores não são simplesmente moldados pelas redes em que estão localizados, mas também influenciam os atores com os quais interagem (Callon \& Law, 1995).

Humanos, objetos e textos se mobilizam, representam e assumem a forma de redes de entidades que estão por trás destes. Callon e Law (1997) afirmam que "os atores são redes e pontos, são indivíduos e coletivos". Analiticamente, um ator humano é um efeito gerado por uma rede de materiais heterogêneos com os quais interage (Law, 1992). Na exemplificação didática de Callon e Law (1997), pode ser tentador afirmar que Andrew é um estrategista, contudo tal afirmativa consiste em um impulso perigosamente enganoso. Andrew o estrategista, é uma rede heterogênea composta por "Andrew + fax + colegas gerentes + secretária + sede + seu PC + o trabalho de cientistas + os memorandos que circulam + os horários preenchidos pelos empregados, (...)” (p. 172). Ou seja, esta combinação de elementos que cria a possibilidade de ação estratégica, uma vez que a capacidade de fazer estratégia é um efeito de um arranjo mais ou menos estável de elementos. Para Vosselman (2014), esse coletivo híbrido (seres humanos e outros seres não humanos) proporciona aos indivíduos uma capacidade de agir e dar significado às ações.

Callon e Law (1997) indicam que, pelo argumento de participação híbrida, a ação não pode ser explicada, de forma reducionista, como uma consequência firme de qualquer ação anterior. As ações são propriedades de entidades associadas, e não apenas propriedade dos humanos. Em outras palavras, qualquer entidade (humana ou não humana) possui o potencial de agir, e a ação é resultado de um processo contínuo de translação, conexões e negociações (Latour, 1999). Para Callon e Law (1997), a ação é uma propriedade coletiva, sem necessariamente ser algo realizado por pessoas no coletivo. "Ninguém mais, em particular, faz qualquer ação" (Latour, 2005, p. 205).

A agência dos seres humanos, como pressuposto, não pode ser compreendida isoladamente da agência de vários não humanos, e vice-versa. Assim, a agência não é uma propriedade de certos tipos de entidades, mas uma propriedade emergente das redes e inter-relações entre atores heterogêneos (Nimmo, 2011). Segundo esse autor, quanto mais atores se inscrevem nestas redes e quanto mais heterogêneos estes forem, mais potente é a agência resultante. Latour (2013) denomina de hibridação a construção de redes complexas entre entidades diversas, como característica definidora da modernidade e chave para seu peculiar dinamismo (p.112). A agência não é uma propriedade exclusiva dos seres humanos, pelo contrário, "os objetos também têm agência" (Latour, 2005, p. 63). A agência é uma propriedade emergente, derivada de arranjos de humanos e não humanos, pois as entidades não existem sozinhas e os agentes são efeitos gerados em uma configuração de diferentes matérias, sendo sempre um produto relacional (Callon \& Law, 1995; Latour, 1999).

A rede é uma expressão para verificar a quantidade de energia, movimento e especificidade do que se pretende especificar. A rede não designa uma 'coisa lá fora', que teria aproximadamente a forma de pontos interligados, bem como um telefone, uma autoestrada ou uma rede de esgoto. Não é nada mais do que um indicador da qualidade de um texto sobre os temas em questão. Ela qualifica sua objetividade, isto é, a capacidade de cada ator para fazer outros atores fazerem coisas inesperadas (Latour, 2005). Para Law (1987) as redes são compostas por um conjunto de elementos heterogêneos (animado e inanimado) que foram ligados uns aos outros por um período de tempo, não possuindo uma formação e uma composição fixa, estável e definitiva, visto que podem ser alteradas a qualquer momento.

Ao contrário de serem dois elementos separados - ator e rede, conforme o nome (ator-rede) pode dar a entender, nesta abordagem os atores são efeitos das redes (Law, 1999). Cabe relembrar que se está em uma ontologia do social em que a realidade não possui um status estável e definitivo. Ou seja, essa realidade é composta por redes de materiais heterogêneas (humanos e não humanos) que estão reunidas (Latour, 1990). Callon e Law (1997) indicam que uma rede relativamente estabilizada também tende a se tornar uma entidade, uma caixa preta, que traduz os vários materiais que a compõem. Neste momento, a rede pode atuar como uma única unidade, que pode ser distinguida do seu ambiente, distinguida como um objeto com sua própria identidade consistente (p. 170). Contudo, sua durabilidade não advém apenas da ligação entre elementos, mas porque cada entidade constitui uma rede em si, de modo que qualquer mudança nas entidades de uma rede-de-atores gera transformações na própria rede (Law, 1987).

A rede, portanto, não é feita de "fio de nylon, palavras ou qualquer substância durável, mas é o traço deixado para trás por algum agente em movimento" (p. 131). As representações gráficas das redes, 
que apenas estabelecem inúmeras ligações entre pontos mais ou menos convergentes, não conseguem retratar o movimento e tornam-se visualmente pobres. Latour (2005) sugere que ao invés de actornetwork, os termos worknet ou action net denominariam de maneira mais fiel o que se quer descrever. 0 termo worknet permite que se explore o trabalho que se passa nas redes de trabalho (networks), sendo tanto um mediador ativo, quanto um conjunto estabilizado de intermediários.

Law (1992) especifica que, ao se explorar uma organização por meio da teoria ator-rede, a organização necessita ser tratada como um efeito ou uma consequência. 0 argumento consiste no entendimento de que uma organização pode ser vista como um conjunto de estratégias que operam para gerar configurações complexas de durabilidade da rede, mobilidade espacial, sistemas de representação e calculabilidade - configurações que têm o efeito de gerar as assimetrias hierárquicas, características da maioria das organizações formais. Sua durabilidade não tem ligação com a materialidade, e sim com o movimento (Latour, 2005). Neste caso, a rede atua como um único bloco (Law, 1992) ou uma caixa preta (Latour, 2005), e desaparece, para ser substituída pela ação em si e representada pelo aparentemente único autor dessa ação. Segundo Law (1992, p. 385) "os padrões de rede que são amplamente executados são muitas vezes aqueles que podem ser pontuados".

No que se refere a espacialidade das redes, Latour (2005) afirma que nenhum lugar pode ser dito como maior do que qualquer outro lugar. Os lugares não diferem em forma ou tamanho, mas na direção dos movimentos para frente e para trás, bem como na natureza do que está sendo transportado. Neste sentido, os agentes não são tratados como intermediários, mas como mediadores. Eles tornam o movimento do social visível, ou seja, uma entidade circulante que já não é composta pelo conjunto obsoleto do que se denominou anteriormente como parte da sociedade (Latour, 2005).

Em referência à relação entre diferentes atores, Latour (2005) sugere que: (i) nenhuma relação é isotópica, uma vez que o que está agindo em um mesmo momento em qualquer lugar é proveniente de muitos outros lugares de muitos materiais e atores distantes; (ii) nenhuma relação é sincrônica, pois a ação sempre foi exercida graças à inversão do ônus da ligação de entidades com duração mais longa ou mais curta; (iii) relações não são sinópticas, o que indica que poucos participantes em um determinado curso de ação são simultaneamente visíveis em qualquer ponto; (iv) relações não são homogêneos, ou seja, a multidão de não humanos, os participantes não-locais também se reúnem para ajudar a realizar o curso de ação; (v) relações não são isobáricas, pois alguns dos participantes estão pressionando fortemente, pedindo para ser ouvidos e levados em conta, enquanto outros são costumes rotineiros e incorporados em hábitos (Latour, 2005).

Neste ponto, faz-se necessário ressaltar a diferenciação realizada por Latour (2005) entre intermediário e mediador. Para o autor, o intermediário, é o que transporta significado ou força, mas sem transformação. A definição do que entra, portanto, é suficiente para definir a saída. Por outro lado, os mediadores são capazes de transformar, traduzir, distorcer e modificar o significado ou os elementos que deveriam transportar. Neste caso, as causas não permitem que efeitos sejam automaticamente deduzidos. A concatenação de mediadores não corresponde às mesmas conexões, e não requer o mesmo tipo de explicação e a mesma retidão de intermediários que transportam uma causa.

Portanto, para a ANT não existe sociedade, nenhum reino social, nenhum laço social, mas existe a tradução entre mediadores que podem gerar associações rastreáveis. A palavra tradução recebe, nesta abordagem, um significado particular: "uma relação que não transporta causalidade, mas que induz dois mediadores a existirem" (Latour, 2005, p. 108). Para Callon (1986) a tradução permite alcançar uma explicação de como alguns conseguem o direito de expressar e representar os muitos atores silenciosos dos mundos sociais e naturais que mobilizaram.

Em termos metodológicos, o pesquisador em campo necessita estar atento aos papéis desempenhados não apenas pelos seres humanos, mas também por seres não humanos, como artefatos e híbridos, estes últimos formados pela interconexão de diferentes tipos de "seres" (atuantes), com capacidade de alterar os cursos de ação uns dos outros. Especificamente, explora-se em um primeiro momento a heterogeneidade e a multiplicidade de participantes (Latour, 2005). Com o foco no fenômeno em estudo em mente, o pesquisador identifica todos os atores (atuantes) que se pode identificar no campo e os quais relacionam-se ao fenômeno em questão. Em um segundo momento, são analisadas as interações entre os atores (previamente identificados), para entender como suas relações formam ou constroem uma "rede" (actor-network). Por fim, aprofunda-se a interpretação das informações e observações realizadas de maneira extensiva e intensiva para entender como um grupo de atores, atuando em conjunto, passou a ter voz única (ou seja, tornou-se um coletivo híbrido 
singularizado) (Latour, 2005). Como trata-se de uma abordagem relacional, o foco está no que acontece entre os atores, para entender como os atores modificam-se interagindo uns com os outros. Em outras palavras, em vez de olhar o que aconteceu cognitiva ou comportamentalmente no nível do indivíduo (tipicamente um ser humano ou um grupo de seres humanos), procura-se entender o que aconteceu "relacionalmente", isto é, compreender como múltiplos (humanos e não humanos) conectam-se, como eles mudam por meio das interações, e como o resultado dessas interações constituem híbridos - como organizações - que também passam a compor e atuar na rede (Law, 1999).

\subsection{Alinhamento entre Sociologia Relacional e Teoria Ator-Rede}

Após apresentar o desenvolvimento do pensamento de cada uma das abordagens separadamente, busca-se indicar os principais pontos de convergência e divergência entre elas. Para isso, foi adotado o modelo de classificação de paradigmas sociológicos proposto por Hassard e Cox (2013), o qual contempla aspectos ontológicos, epistemológicos, metodológicos e a natureza humana. Figura 2: Comparação da Sociologia Relacional e a ANT por meio da classificação de Hassard e Cox (2013).

\begin{tabular}{|c|c|c|c|}
\hline Aspecto & Classificação & $\begin{array}{c}\text { Sociologia Transacional ou } \\
\text { Relacional Profunda }\end{array}$ & Teoria Ator-Rede \\
\hline Ontologia & Relativista & $\begin{array}{l}\text { A relação é o ponto de partida } \\
\text { (Donati, 2011), e a definição de } \\
\text { sujeito e objeto só pode se dar } \\
\text { relacionalmente. }\end{array}$ & $\begin{array}{l}\text { Parcimônia ontológica (Latour, 2005), evita- } \\
\text { se suposições a priori. }\end{array}$ \\
\hline Epistemologia & Relacionista & $\begin{array}{l}\text { Há apenas a relação entre } \\
\text { entidades, e não propriedades } \\
\text { intrínsecas (Emirbayer, 1997). }\end{array}$ & $\begin{array}{l}\text { Entidades tomam sua forma e adquirem seus } \\
\text { atributos como resultado de suas relações } \\
\text { com outras entidades (Law, 1999). }\end{array}$ \\
\hline Metodologia & Reflexiva & $\begin{array}{l}\text { Conceitos deixam de ser uma } \\
\text { expressão categórica singular, e } \\
\text { passam a ser entendidos como } \\
\text { envolvidos em redes relacionais } \\
\text { complexas que são intersubjetivas } \\
\text { e públicas (Emirbayer, 1997). }\end{array}$ & $\begin{array}{l}\text { Ao invés da segurança de categorias } \\
\text { analíticas pré-concebidas, o pesquisador } \\
\text { busca reconhecer os elementos díspares que } \\
\text { rotineiramente entram nos processos } \\
\text { complexos e ativos pelos quais as pessoas dão } \\
\text { sentido ao mundo (McNaghten \& Urry, 1998). }\end{array}$ \\
\hline $\begin{array}{l}\text { Natureza } \\
\text { Humana }\end{array}$ & Desconstrucionista & $\begin{array}{l}\text { Agência emerge de nosso } \\
\text { relacionamento emocional com os } \\
\text { outros, como relações sociais } \\
\text { reveladas no tempo e no espaço } \\
\text { (Burkitt, 2016). }\end{array}$ & $\begin{array}{l}\text { A agência não é uma propriedade de certos } \\
\text { tipos de entidades, mas uma propriedade } \\
\text { emergente das redes e inter-relações entre } \\
\text { atores heterogêneos (Nimmo, 2011) }\end{array}$ \\
\hline
\end{tabular}

Fonte: Elaborado pelo autor com base na proposta de classificação de paradigmas sociológicos de Hassard e Cox (2013).

Por meio da análise da Figura 2, percebe-se o alinhamento entre a perspectiva de tradição estruturalista denominada Sociologia Relacional e a ANT, com base na antropologia. Esse alinhamento entre as abordagens tem sido anunciado de maneira discreta na literatura. Por exemplo, Dépelteau (2013) reconhece que muitos sociólogos relacionais não querem ser associados com a Teoria Ator-Rede, mas que as ideias de Bruno Latour são análogas as da sociologia relacional. 0 autor afirma que a sociologia relacional profunda pode ser relacionada "com abordagens contemporâneas influentes, como a Teoria Ator-Rede de Bruno Latour e outros" (Dépelteau, 2013, p. 184). Além disso, em alguns artigos na área de organizações, autores da sociologia relacional (Emirbayer) e ANT (Latour) são citados conjuntamente, como se conferissem a mesma escola de pensamento. Exemplos deste tipo de citação podem ser observados em Hassard e Cox (2013) e Nicolini e Monteiro (2017).

Contudo, a obra de Mützel (2009) estabelece de maneira mais explícita laços entre as duas abordagens. A autora utiliza a Sociologia Relacional em sua versão mais ampla (Emirbayer, 1997), ao invés da sociologia relacional profunda de Dépelteau (2013) a qual, na visão dos autores deste trabalho, já aparam arestas existentes entre tais perspectivas.

Dentre as similaridades apresentadas por Mützel (2009), destaca-se que ambas as abordagens: (i) rejeitam reificações a priori, como por exemplo 'o social' e 'a sociedade'; (ii) resistem à referência ao representacional ou ao simbólico, uma vez que concentram suas análises empíricas na realidade material e os significados que os próprios atores atribuem a ele em lutas e controvérsias; (iii) consideram a produção de sentido como uma atividade de conexão/desconexão e analisam como os atores são criados por meio da colaboração de outros atores em diferentes contextos; (iv) entendem que 
os laços precedem os nós (a relação vem primeiro), e compartilham uma compreensão das redes como formações dinâmicas e socioculturais; (v) utilizam métodos e dados qualitativos e também utilizam análises visuais e formais das redes sociais; (vi) preocupam-se com a produção de sentido e a emergência colaborativa de atores, que resulta em transformações (transação - tradução) em vez de combinações de entidades envolvidas.

No que se refere particularmente a questão da agência, ambas as abordagens passam a dar foco ao "que" age em detrimento ao "quem" age (Sayes, 2014). A máxima apresentada por Donati (2011): “... no início há a relação", contempla ontologicamente o entendimento da formação da realidade em ambas as abordagens. Ou seja, uma vez que nenhuma entidade é discreta, substancialmente pré-formatada ou claramente separada de seu "contexto", a ação é necessariamente mediada e a agência é, portanto, dissociada dos critérios de intencionalidade, subjetividade e livre arbítrio. Em decorrência, a ideia de que exista qualquer entidade pré-formatada (estrutura), e também a ideia de que o indivíduo pode interagir diretamente com uma estrutura (padrão social) são descartadas nestas concepções (Burkitt, 2016). Latour (2005) indica que para que uma ação seja transportada de um lugar para outro ela precisa de um veículo ou um condutor, ou seja, há sempre um processo de tradução (Callon, 1986) ou transação (Emirbayer, 1997), em detrimento a uma relação de causalidade.

Mützel (2009) ainda identifica que a questão de elementos não humanos e também a forma de se pensar a coleta de dados das pesquisas são as principais diferenças entre as abordagens em questão. A teoria Ator-Rede, pelo princípio da assimetria generalizada, estabelece que humanos e não humanos não podem receber uma diferenciação anterior. A sociologia relacional também incorporou atores não humanos em suas análises. Dépelteau (2013) indica que "constantemente se transaciona com outras entidades humanas e não humanas, feitas de coisas materiais como células, sangue, plástico folhas, madeira, e assim por diante" (p. 187). Contudo, Mützel (2009) indica que eventualmente para a Sociologia Relacional apenas os humanos são capazes de contar histórias.

Quanto aos elementos não humanos verifica-se que ambas as abordagens têm trabalhado para aprimorar a análise de atores não humanos em suas pesquisas. McFarlane (2013), por exemplo, critica o humanismo reacionário que ainda é dominante na abordagem da sociologia relacional, e sugere que a própria abordagem da ANT pode ser uma alternativa para "dessubstanciar o humano" (p. 62). Segundo McFarlane (2013) não pode haver "humano-social" sem um acompanhamento "não humano-social" e negar esse fato não serve a ninguém, em especial à sociologia relacional. Em contrapartida, Rudolf (2012) critica as próprias pesquisas da teoria Ator-Rede. 0 autor afirma que os não humanos ainda são reduzidos ao status de objetos, inertes e à disposição dos humanos, e que se faz necessário ampliar a discussão sobre a mediação realizada por não humanos.

A outra diferença apontada por Mützel (2009) refere-se ao entendimento da postura do pesquisador (observador) na coleta de dados. A autora verificou que, em pesquisas embasadas em uma aproximação da teoria Ator-Rede, a abordagem é eminentemente aberta e interpretativa, na qual o pesquisador segue o ator (actant) em suas próprias conexões (do ator). Em contrapartida, na sociologia relacional, apesar de também apresentar uma abordagem vivencial de pesquisa, o analista é quem atribui 'quem' e 'o que' conta para ele.

As diferenças apontadas por Mützel (2009), em um olhar ontológico-epistemológico, não são impeditivas do alinhamento entre as abordagens. E sobremaneira, deveriam ser consideradas como oportunidade para aprimoramento, conforme se tem observado em algumas pesquisas (Rudolf, 2012; McFarlane, 2013; Dépelteau, 2015). Cabe ainda salientar que a convergência de ambas as abordagens não significa a unificação teórica entre ambas. Contudo acredita-se que a discussão do papel de estrutura-agência e reflexividade da tradição da sociologia relacional, em adição aos aspectos da aproximação do campo empírico, dos atores não humanos e da postura do pesquisador da teoria AtorRede, podem dar subsídios para amadurecimento das duas correntes de pensamento e, principalmente, ressoar no aprimoramento e nas inovações teóricas em outras áreas da ciência que se utilizam de tais abordagens.

\section{Repercussões para os Estudos Organizacionais (EOR)}

Há algum tempo tem-se discutido sobre a falta de renovação nas teorias da área de Estudos Organizacionais. E a discussão principalmente se dá em dois sentidos, mutuamente complementares e não excludentes: (i) amadurecimento e inovação nas teorias da área; e (ii) aproximação das teorias com a realidade empírica. Assim, o fortalecimento de uma abordagem relacional ajuda a romper com a 
compreensão existente de organizações pré-formatadas e desafia o pensamento dominante de substância (Langley \& Tsoukas, 2017).

Uma primeira especificidade de uma abordagem relacional, aplicada aos estudos organizacionais, consiste em reconsiderar a própria noção de organização. Em contraste com as abordagens estruturais deterministas ou co-deterministas (Emirbayer, 1997), o que é estudado sob a perspectiva da abordagem relacional não pode ser organizado em uma forma topologicamente homogênea, nem como um único objeto, nem como diversidade dentro de um espaço único (Law, 1999). Ou seja, qualquer ideia de estrutura (e o de ligações estáticas entre substâncias inertes) é abandonada em favor da análise de conexões relacionais entre atuantes.

Para tanto, as organizações, quando encaradas sob o olhar das teorias de cunho relacionais (e.g. sociologia relacional profunda e teoria Ator-Rede), podem ser entendidas como elementos híbridos, fruto do processo de transação de diferentes atores (atuantes). Ou seja, cada organização é construída e adquire seus atributos por meio do conjunto de relações que foram estabelecidas com os outros, existindo e sendo sustentada por meios dessas relações (Law, 1999). Além de sua unidade aparente, as organizações são caracterizadas como construções relacionais de atores "múltiplos e incomensuráveis", em que cada um acrescenta seu modelo disposicional (atitudes historicamente influenciadas), e por meio do qual as realizações comuns podem ser configuradas e desveladas. Essas realizações nunca são absolutas ou fixas, mas evoluem em seu escopo e modalidade: cada "organização" emerge de um arranjo (ou rede) de relacionamentos estáveis, e só existe dentro dessa rede, pois "sobrevive" das relações que se estabelecem entre si e com outras entidades (Donati, 2011).

Uma segunda característica distintiva da abordagem relacional (tratada de maneira ampla) consiste na (re)conceituação do processo organizativo (organizing). A "natureza" do processo tem sido questionada muitas vezes (Nayak \& Chia, 2011), contudo nesta linha de pensamento o processo organizativo perde o caráter simbólico e interpretativo (Weick, 1969). Em vez disso, considera-se que um "processo organizativo" pode ser entendido como o movimento das redes heterogêneas que possuem interesses em comum. Ou seja, não são passos (mais ou menos abstratos) para frente ou para trás, mas deslocamentos de uma rede de atuantes no tempo, espaço e em sua própria forma de disposição, os quais modificam a realidade da própria rede em questão.

A terceira repercussão consiste em repensar a questão da agência em um processo organizativo. Em estudos de organizações, via de regra, estas são tratadas sob uma lógica burocrática (Mintzberg \& Waters, 1990). Ou seja, imputa-se à organização uma capacidade antropocêntrica, advinda, via um processo consequencialista, de características cognitivas, sociais e/ou políticas de um indivíduo ou grupo de indivíduos. Na lógica relacional, no entanto, há uma enorme incerteza sobre "quem", ou mesmo, "o que" está agindo (Sayes, 2014). Em outras palavras, "os humanos não são nem causa pura, nem efeito puro, mas parte do mundo em seu devir em aberto" (Barad, 2003, p. 822). Assim, conhecer uma organização não implica mais explorar unicamente o trabalho de um indivíduo (ou grupo de indivíduos), mas exige o estudo das redes de relações que mediam e sustentam a organização. Aproximar-se de uma organização (como uma rede de relações) significa que os seres humanos são apenas um elemento desta rede. Portanto, pensar, agir, decidir, organizar, não são mais atributos conferidos aos seres humanos, mas são gerados em redes que passam e se ramificam dentro e fora do corpo (Law, 1992).

Verifica-se que estas abordagens tem uma implicação clara em termos de agência. Uma organização, como qualquer outro elemento da rede de relações, gera algum efeito sobre a rede e representa a realidade em andamento. E, em decorrência, a organização como fruto e parte de uma rede, também participa da ação, bem como os indivíduos, os artefatos e os textos dispostos em seu entorno. Este entendimento é compartilhado pela teoria Ator-Rede e também pela Sociologia Relacional, no que se pode denominar de paradigma pós-estrutural (Hassard \& Cox, 2013) e pós-humanista (McFarlane, 2013), na medida em que combinam uma visão descentralizada da agência com uma ontologia relacional.

Em adição, por meio das abordagens evidenciadas neste trabalho, convida-se os estudiosos a desumanizarem a agência de qualquer ação humana, única, intencional e reflexiva do ator racional, e em vez disso ver a agência distribuída, de modo que o ator "não é a fonte de uma ação, mas o alvo em movimento de uma vasta gama de entidades as quais relacionam-se em direção a ele" (Latour, 2005, p. 46). Nessa perspectiva, humanos, artefatos, híbridos são dotados da capacidade de participar e alterar o curso de ação de cada um. 
Neste sentido, a perspectiva filosófica da relacionalidade, trabalhada nesta revisão de literatura por meio da Sociologia Relacional e da Teoria Ator-Rede, oferece oportunidades de aproximação do pesquisador com o campo, por meio de pesquisas vivenciais e longitudinais, sem reificar ou objetificar os elementos em estudo. Tais abordagens ajudam a perceber a organização como um processo social relacional e, neste sentido, diferentes explicações podem emergir das transações entre o observador e as transações observadas (Dépelteau, 2015).

\section{Considerações Finais}

Neste trabalho de revisão de literatura explorou-se o alinhamento entre a sociologia relacional e a teoria ator-rede e as suas repercussões para a área de estudos organizacionais. Utilizou-se, para tanto, a estrutura de classificação de paradigmas sociológicos para apresentar a aproximação ontológica, epistemológica e metodológica das abordagens.

No que se refere à contribuição desta aproximação entre a sociologia relacional e a ANT para a área de estudos organizacionais verifica-se uma oportunidade de revisar, ontologicamente e epistemologicamente falando, os pressupostos da área de conhecimento (Alvesson \& Sandberg, 2011), e em decorrência aprimorar e inovar as teorias da área (Suddaby, Hardy, \& Huy, 2011; Tsoukas, 2017). Neste intuito, no que tange a área de estudos organizacionais, abordagens sob o prisma da relacionalidade, permitem: (i) reconsiderar a própria noção de organização, para além dos paradigmas deterministas e co-deterministas (Emirbayer, 1997), (ii) (re)conceituar os processos organizativos (organizing), como o movimento das redes de múltiplos atuantes no tempo, no espaço e em sua própria forma de disposição entre si, (iii) repensar a questão da agência no processo organizativo, desumanizando a agência de qualquer ação unicamente humana, intencional e reflexiva, permitindo aos não humanos (e.g. artefatos, híbridos) também participarem e alterarem o fluxo de ação.

Ressalta-se que, mesmo assim, é muito fácil reificar as entidades que se quer relacionar (Dépelteau, 2013). Emirbayer (1997) indica que dificilmente se ouvirá "Olhe para o fluxo incessante de água", pois o que se diz é "Olhe o quão rápido o rio está fluindo" (p. 283). 0 pensamento de substância está ainda engendrado no pensamento ocidental (Nayak \& Chia, 2011) e promove a redução de processos para condições estáticas, o que Elias (1978) denomina de "redução de processo". Apesar de serem reduções, estas passam a ser naturalmente empregadas nas transações entre indivíduos e tornam-se autoexplicativas para as pessoas que cresceram com este tipo de linguagem (Emirbayer, 1997). Apesar das propostas apresentarem direções de pesquisa (Emirbayer, 1997), para que as discussões da Sociologia Relacional e da Teoria Ator-Rede reverberem nos estudos organizacionais, fazse necessária uma mudança paradigmática dos pesquisadores na área. Não se trata apenas de adotar novas perspectivas teóricas mas, fundamentalmente, de mover-se (o pesquisador) para uma maneira diferente de perceber a realidade, o que não é simples (Marsh \& Furlong, 2002). Em Latour (2005, p. 141-156), o autor explora de maneira bem-humorada a dificuldade do pesquisador em mover-se para uma perspectiva ator-rede, e os problemas e confusões da adoção teórica sem o devido alinhamento ontológico-epistemológico.

No que se refere a oportunidades de pesquisa, verifica-se que as abordagens aqui analisadas podem (i) fomentar o aumento de complexidade das explicações teóricas da área, incluindo o tempo em suas explanações (Tsoukas, 2017); (ii) definitivamente esvair-se de um pensamento social-humanista, dando voz à materialidade e aos elementos não humanos em suas observações (Latour, 2005; McFarlane, 2013); (iii) aproximar-se das experiências sociais das pessoas, em busca de explicações que ressoam a realidade das organizações (Dépelteau, 2015).

Finalmente, cabe destacar que, com base na ontologia das abordagens discutidas neste trabalho, qualquer possibilidade de explicação necessita vir de uma experiência empírica de pesquisa. Portanto, as construções "lógicas" exercitadas nesta revisão de literatura não podem ser tomadas como definitivas, nem pelo autor, nem pelo leitor, mas apenas como um exercício de amadurecimento filosófico. Em termos de inovação teórica, as explicações precisarão ser novamente "remontadas" (Latour, 2005) a partir da imersão do pesquisador no seu campo de interesse.

\section{NOTAS}

1 - Inter-actants é o termo sugerido por Burkitt (2016), para sugerir que não existe sujeito sem previamente haver relações. Ainda na tradição da sociologia relacional, Dépelteau (2013) utiliza o termo transactors. Na abordagem da Teoria Ator-Rede, Callon \& Latour (1992) sugerem o termo actant, o qual 
relaciona ao mesmo conceito de sujeito interdependente, mas que engloba os elementos não humanos inicialmente negligenciados pela sociologia relacional.

2 - A definição de um entendimento de relação utilizando-se a palavra interação é criticado por Dépelteau (2013). 0 autor afirma que o termo é utilizado por abordagens co-deterministas para descrever a relação causal entre sujeito (indivíduo) e estrutura. Dépelteau (2013) apresenta o termo transação, já proposto por Emirbayer (1997). Contudo, Burkitt (2016) indica que interação não pressupõe essa relação agente-estrutura, pois o significado etimológico da palavra indica que interação "consiste na formação de relações significativas e identidades por meio destas relações" (p. 332). Neste sentido, transação (Dépelteau, 2013) e interação (Burkitt, 2016) apresentam o mesmo significado. 0 termo também se aproxima do conceito de mediação apresentado por Latour (2005).

\section{Referências}

Alvesson, M., \& Sandberg, J. (2011). Generating research questions through problematization. Academy of Management Review, 36(2), 247-271.

Archer, M. S. (1995). Realist Social Theory: The Morphogenetic Approach. Cambridge: Cambridge University Press.

Barad, K. (2003). Posthumanist performativity: Toward an understanding of how matter comes to matter. Signs, 28(3), 801-831.

Bueger, C. (2013). Actor-Network Theory, Methodology, and International Organization. International Political Sociology, 7(3), 338-342.

Burkitt, I. (2016). Relational agency: Relational sociology, agency and interaction. European Journal of Social Theory, 19(3), 322-339.

Callon, M. (1986). Some elements of a sociology of translation: domestication of the scallops and the fishermen of St Brieuc Bay. The Sociological Review, 32(S1), 196-233.

Callon, M., \& Latour, B. (1992). Don't throw the baby out with the bath school! A reply to Collins and Yearley. In: A. Pickering (ed.), Science as Practice and Culture. Chicago: University of Chicago Press, ,343368.

Callon, M., \& Law, J. (1995). Agency and the hybrid collectif. The South Atlantic Quarterly, 94 (2), 481507.

Callon, M., \& Law, J. (1997). After the individual in society: Lessons on collectivity from science, technology and society. Canadian Journal of Sociology, 22 (2), 165-182.

Chia, R., \& Holt, R. (2006). Strategy as practical coping: A Heideggerian perspective. Organization Studies, 27(5), 635-655.

Collins, H. M., \& Yearley, S. (1992) Epistemological Chicken. In: A. Pickering (ed.), Science as Practice and Culture. Chicago: University of Chicago Press, pp. 301-326.

Dépelteau, F. (2013). What Is the Direction of the 'Relational Turn’?. In: C. Powell \& F. Dépelteau (Ed.). Conceptualizing Relational Sociology: Ontological and Theoretical Issues, Palgrave Macmillan: New York, 163-185.

Dépelteau, F. (2015). Relational sociology, pragmatism, transactions and social fields. International Review of Sociology, 25(1), 45-64.

Dewey, J., \& A. Bentley (1949) Knowing and the Known. Westport, CT: Greenwood Press.

Donati, P. (2011). Relational sociology: a new paradigm for the social sciences. London: Routledge.

Elias, N. (1978). What Is Sociology? New York: Columbia University Press.

Emirbayer, M. (1997). Manifesto for a relational sociology 1. American Journal of Sociology, 103(2), 281317.

Giddens, A. (1984). A Constituição da Sociedade. 3a. ed. São Paulo: Editora WMF Martins Fontes. Versão em português de 2009.

Hassard, J., \& Cox, J. (2013). Can sociological paradigms still inform organizational analysis? A paradigm model for post-paradigm times. Organization Studies, 34(11), 1701-1728.

Langley, A., \& Tsoukas, H. (2017) Introduction: Process thinking, process theorizing and process researching. In: Langley, A., \& Tsoukas, H. (eds) The SAGE Handbook of Process Organizational Studies. London: Sage, pp. 1-25.

Latour, B., \& Woolgar, S. (1986) Laboratory life: the construction of scientific knowledge. Princeton, NJ: Princeton University Press. 
Latour, B. (1987). Science in action. Cambridge: Harvard University Press.

Latour, B. (1990). Technology is society made durable. The Sociological Review, 38(S1), 103-131.

Latour, B. (1999). On recalling ANT. The Sociological Review, 47(S1), 15-25.

Latour, B. (2005). Reassembling the social: An introduction to actor-network-theory. Oxford: Oxford University Press.

Latour, B. (2013). Jamais fomos modernos. São Paulo: Editora 34.

Law, J. (1987). Technology and heterogeneous engineering: The case of Portuguese expansion. In: Bijker, W., Hughes, T., \& T. Pinch. The social construction of technological systems: New directions in the sociology and history of technology. London: MIT Press, 1-134.

Law, J. (1992). Notes on the theory of the actor-network: Ordering, strategy, and heterogeneity. Systems Practice, 5(4), 379-393.

Law, J. (1999). After ANT: complexity, naming and topology. The Sociological Review, 47(S1), 1-14.

Marsh, D., \& Furlong, P. (2002). A skin, not a sweater: ontology and epistemology in political science. In: D. Marsh, \& G. Stoker, (eds.). Theory and methods in political science. New York: Pallgrave McMillan, 1741.

McFarlane, C. (2013). Relational sociology, theoretical inhumanism, and the problem of the nonhuman. In: C. Powell \& F. Dépelteau (Ed.). Conceptualizing Relational Sociology: Ontological and Theoretical Issues, New York: Palgrave Macmillan, 45-66.

McNaghten, P., \& J. Urry (1998) Contested Natures, London: Sage.

Mintzberg, H. \& Waters, J. (1990). Studying deciding: An exchange of views between Mintzberg and Waters, Pettigrew, and Butler. Organization Studies, 11(1), 1-6.

Mützel, S. (2009). Networks as culturally constituted processes: a comparison of relational sociology and actor-network theory. Current Sociology, 57(6), 871-887.

Nayak, A., \& Chia, R. (2011). Thinking becoming and emergence: process philosophy and organization studies. In: H. Tsoukas; \& R. Chia (Ed.). Philosophy and Organization Theory (Research in the Sociology of Organizations, Volume 32). London: Emerald Group Publishing Limited. 281 - 309.

Nicolini, D., \& Monteiro, P. (2017). The practice approach in organizational e management studies. Chapter 7. In: A. Langley \& H. Tsoukas (eds.). The SAGE Handbook of Process Organization Studies. London: Sage.

Nimmo, R. (2011). Actor-network theory and methodology: Social research in a more-than-human world. Methodological Innovations Online, 6(3), 108-119.

Reed, M. I. (1997). In praise of duality and dualism: rethinking agency and structure in organizational analysis. Organization Studies, 18(1), 21-42.

Rudolf, F. (2012). Questioning the human/non-human distinction.In: J. H. Passoth, B. Peuker, \& M. Schillmeier (eds.). (2012). Agency without actors? new approaches to collective action (Vol. 58), New York: Routledge.

Sandberg, J., \& Alvesson, M. (2011). Ways of constructing research questions: gap-spotting or problematization? Organization, 18(1), 23-44.

Sayes, E. (2014). Actor-Network Theory and methodology: Just what does it mean to say that nonhumans have agency? Social Studies of Science, 44(1), 134-149.

Seidl, D., \& Whittington, R. (2014). Enlarging the strategy-as-practice research agenda: Towards taller and flatter ontologies. Organization Studies, 35(10), 1407-1421.

Suddaby, R., Hardy, C., \& Huy, Q. N. (2011). Where are the new theories of organization? Academy of Management Review, 36 (2) 236-246.

Tsoukas, H. (2017). Don't simplify, complexify: from disjunctive to conjunctive theorizing in organization and management studies. Journal of Management Studies, 54 (2), 132-153.

Vosselman, E. (2014). The 'performativity thesis' and its critics: Towards a relational ontology of management accounting. Accounting and Business Research, 44(2), 181-203.

Weick, K.E. (1969) The social psychology of organizing. Reading, MA: Addison-Wesley.

Weick, K. E. (2001). Gapping the relevance bridge: Fashions meet fundamentals in management research. British Journal of Management, 12(s1), S71-S75. 